\title{
Cardiac catheterization and percutaneus catheter in grown-up congenital heart diseases: single center experience at developing country
}

\author{
Luh G.A.P. Dewi, Ni P.V.K. Yantie, Eka Gunawijaya
}

Department of Child Health, Faculty of Medicine, Universitas Udayana, Integrated Cardiac Service, Sanglah Hospital, Denpasar, Indonesia

\section{ABSTRACT}

Background: Grown-up congenital heart disease (GUCH) patients are unique and challenges especially at developing country. The numbers of diagnostic as well as interventional cardiac catheterization procedures in GUCH patients are growing. The aim of this study was to report the outcome of cardiac catheterization including intervention procedure in GUCH.

Methods: The descriptive study was conducted at Sanglah Hospital, Denpasar, Bali, Indonesia. All patients (age of more than 12 years) who underwent cardiac catheterization from 2011 until 2017 were included in this study. Patients, characteristic, types of catheter procedures, immediate complications, and outcomes were documented.

Results: A total 54 subjects were included with median age of 23 years and $70 \%$ were female. The first symptom that brought patients to hospital is dyspnea $46 \%$ and palpitation $32 \%$. Five subjects underwent a diagnostic catheter procedure and 49 (91\%) diagnostic and catheter based interventions. Transcatheter interventions procedures included atrial septal defect (ASD) (success rate of 20 per 21), patent ductus arteriosus (PDA) (success rate of 16 per16), ventricular septal defect (VSD) (success rate of 9 per 9), pulmonal stenosis (PS) (success rate of 1 per 2), and aortic stenosis (AS) (success rate of 1 per 1). The complications encountered were transient dysrhythmias in 15 subjects, device embolization in 4 subjects, massive bleeding in 1 subject, and overall mortality in 2 subjects.

Conclusion: The number of the catheterization interventions in GUCH was 91\% and ASD device closure was the most common procedure. Transcatheter intervention has a high procedural success rates (96\%) and low procedural-related complications.

Keywords: catheterization, grown-up congenital heart disease, interventions

pISSN: 0853-1773• eISSN: 2252-8083• https://doi.org/10.13181/mji.v27i1.2284 • Med J Indones. 2018;27:38-43

- Received 18 Sep $17 \cdot$ Accepted 16 Mar 2018

Corresponding author: Luh G.A.P. Dewi

ayupramithadewi@gmail.com

Copyright @ 2018 Authors. This is an open access article distributed under the terms of the Creative Commons Attribution-NonCommercial 4.0 International License (http://creativecommons.org/licenses/by-nc/4.0/), which permits unrestricted non-commercial use, distribution, and reproduction in any medium, provided the original author and source are properly cited. 
The advances of diagnostic and interventional cardiology have made the life expectancy rate of babies born with congenital defects increased. Nowadays, the number of patients with congenital heart defects who manage to reach adulthood increased and make a specific population as grown-up congenital heart (GUCH) patient. In developing country population of GUCH will reach 20,000 in coming years and nearing 1 million in North America; and estimated to be roughly 100,000 in Spain. Approximately 60\% cases congenital heart disease are diagnosed in infant aged $<1$ year, 30\% in children, and $10 \%$ in adults. ${ }^{1,2}$ Not all GUCH patients has been diagnosed or intervened during childhood. GUCH patients are usuallyintervened through transcatheter,surgeries, and or the combination of both treatments. Cardiac catheterization is now reserved for diagnostic of specific anatomical and physiological problems, or for intervention. There is an increase in the number of transcatheterization procedure intervention in GUCH disease in which surgery are no longer necessary for some patients. In some cases, the best treatment for congenital heart disease is the combination between catheterization intervention and surgery. ${ }^{3}$ Cardiology services in Indonesia face many problems such as lack of access to pediatric cardiac center, shortage of well trained professional specialist for pediatric cardiac care, and lack of facilities for pediatric cardiac care unit. ${ }^{4}$

More than $90 \%$ patients survive after transcatheterization, and the long term complications that may occur to patients with GUCH disease are arrhythmia, ventricular dysfunction, infective endocarditis, stroke, pulmonary hypertension, restrictive left ventricular compliance (diastolic dysfunction) after closure, and heart failure. ${ }^{5,6}$ In addition to the above problems, the publication of GUCH is very limited. There is no data regarding pattern of GUCH disease intervention in Indonesia. Children with heart defect who underwent intervention is seven times more than adult patients. Thus, this study was aimed to reportcardiac diagnosis and intervention of GUCH patients in Sanglah Hospital.

\section{METHODS}

This descriptive study was conducted in Sanglah Hospital, Denpasar, Bali, Indonesia.
All patients (age of more than 12 years) who underwent cardiac catheterization from 2011 until 2017, were included in the study. This research has been approved by Ethics Committee of Faculty of Medicine Universitas Udayana with number of 1843/UN.14.2/KEP/2017. Sample size was calculated with type I error was $5 \%$, the prevalence in previous research is $85 \%$, and the precision was $10 \%$; hence minimal sample size was 49 subjects. ${ }^{3}$ The patients' demographic (such as age, gender, height, and weight), the types of (interventional or diagnostic studies), results, total procedural time, fluoroscopy, oxygen saturations and pressure recordings, immediate complications, and outcomes were documented.

Transcatheterization is divided into two groups: therapeutic catheterization and diagnostic catheterization, based on clinical manifestation and echocardiographic examination. Therapeutic catheterization is said to be successful if the closure is performed completely. Residual, and in the case of stenosis defect, is said to be successful if the stenosis can be released completely. Embolization occurs when the device used to close the defect breaks loose. In the end of the catheterization, the type of procedure, result, procedural time, fluoroscopy time, pulmonary artery (PA) resistance index, and early complication were recorded. One day after catheterization, the patients undergo reevaluation of echocardiography in order to check the result of the closure. All data were entered in Statistical Package for the Social Sciences (SPSS). Descriptive analyses were applied as appropriate.

\section{RESULTS}

A total of 54 subjects were included in this study with median age was 23 years (range 13-59 years) and 70\% were females. Most of them were symptomatic upon presentation with dyspnea on exertion being the most common presenting symptom. Atrial septal defect (ASD) was the most common cardiac malformation reported (Table 1 ).

Out of the 54 subjects, 49 (91\%) subjects underwent therapeutic catheterization while $5(9 \%)$ subjects underwent diagnostic 
catheterization due to ASD with nonreactive pulmonary hypertension $(n=3)$ and doubly committed subarterial (DCSA) ventricular septal defect (VSD) with right coronary cusp (RCC) prolapse $(n=2)$ on echocardiography evaluation before procedure. Therefore, 45 had met successful criteria while 4 subjects unsuccessful (1 subject device deployed failure, and 1 subject has partial released of

Table 1. Patient's demographic

\begin{tabular}{|c|c|}
\hline Characteristics & $\begin{array}{c}\text { Subjects } \\
\mathrm{n}=54\end{array}$ \\
\hline Age during intervention, median, IQR, years & $23(13-59)$ \\
\hline $\begin{array}{l}\text { Age when diagnosed with CHD, median, IQR, } \\
\text { years }\end{array}$ & $20.5(6-56)$ \\
\hline Sex male, n (\%) & $16(30)$ \\
\hline Weight, mean (SD), kg & $50.6(13)$ \\
\hline Height, mean (SD), cm & $157.9(11.5)$ \\
\hline \multicolumn{2}{|l|}{ Body mass index, $\mathrm{n}(\%)$} \\
\hline Underweight $<18,5 \mathrm{~kg} / \mathrm{m}^{2}$ & $19(35)$ \\
\hline Normal $18.5-24.9 \mathrm{~kg} / \mathrm{m}^{2}$ & $28(52)$ \\
\hline Obese $25-29.9 \mathrm{~kg} / \mathrm{m}^{2}$ & $7(13)$ \\
\hline \multicolumn{2}{|l|}{ First symptom, n (\%) } \\
\hline Palpitation & $17(32)$ \\
\hline Chest pain & $12(22)$ \\
\hline Dyspnea on exertion & $25(46)$ \\
\hline Murmur (abnormal heart sound) & $2(4)$ \\
\hline Fatigue & $11(20)$ \\
\hline \multicolumn{2}{|l|}{ Vital signs } \\
\hline Systolic, mean (SD), mmHg & $108.6(14.7)$ \\
\hline Diastolic, mean (SD), mmHg & $63.8(9.2)$ \\
\hline Pulse, mean (SD), bpm & $80.3(11.7)$ \\
\hline Breath rate, mean (SD), bpm & $20.4(3.6)$ \\
\hline Oxygen saturation, mean (SD), \% & $98(1.3)$ \\
\hline \multicolumn{2}{|l|}{ Laboratories measurements } \\
\hline Hemoglobin, mean (SD), mg/dL & $14.0(2.0)$ \\
\hline Hematocrit, mean (SD), \% & $43(6.0)$ \\
\hline \multicolumn{2}{|l|}{ Type of heart disease, n (\%) } \\
\hline PDA & $16(30)$ \\
\hline VSD & $11(20)$ \\
\hline ASD & $24(44)$ \\
\hline PS & $2(4)$ \\
\hline AS & $1(2)$ \\
\hline
\end{tabular}

$\mathrm{IQR}=$ interquartile range; $\mathrm{CHD}=$ congenital heart defect; $\mathrm{PDA}=$ patent ductus arteriosus; $\mathrm{VSD}=$ ventricular septal defect; $\mathrm{ASD}=$ atrial septal defect; $\mathrm{PS}=$ pulmonary stenosis; $\mathrm{AS}=$ aortic stenosis stenosis, and 2 subjects has immediately device embolization) (Figure 1).

Transcatheter interventions procedures included atrial septal defect (ASD) closure (success rate 20/21), patent ductus arteriosus (PDA) occlusion (success rate 16/16), ventricular septal defect (VSD) closure (success rate 9/9), pulmonary stenosis (PS) ballooning (success rate $1 / 2$ ), and aortic stenosis (AS) ballooning (success rate $1 / 1$ ). The longer procedure time and fluoroscopy time were found in therapeutic catheterization (Table 2).

Early complications reported after catheterization were minimal hemorrhage in site of puncture (69\%), dysrhythmia such as ventricular tachycardia, ventricular extrasystole, and ventricular fibrillation $(28 \%$ for all three). Mean ejection fraction one day after catheterization was $67.8 \%$. There were $96 \%$ of the patients who survived composed of $96.3 \%$; and only two of them were died (one patient died on $6^{\text {th }}$ and another patient died $2^{\text {nd }}$ day after transcatheter procedure due to ventricular tachycardia and pulmonary hypertension crisis)

Table 2. Characteristic of catheterization procedures

\begin{tabular}{|c|c|c|}
\hline Variables & $\begin{array}{l}\text { Therapeutic } \\
(\mathrm{n}=49)\end{array}$ & $\begin{array}{c}\text { Diagnostic } \\
(\mathrm{n}=5)\end{array}$ \\
\hline $\begin{array}{l}\text { Procedure time, mean (SD), } \\
\text { minutes }\end{array}$ & $98.2(39.6)$ & $57.6(18.8)$ \\
\hline $\begin{array}{l}\text { Fluoroscopy time, mean (SD), } \\
\text { minutes }\end{array}$ & 24.7 (13.8) & $12.1(3.1)$ \\
\hline Flow ratio, mean (SD), minutes & $2.6(2.6)$ & $1.2(0.3)$ \\
\hline $\begin{array}{l}\text { PA resistant index, mean (SD), } \\
\text { minutes }\end{array}$ & $4.6(5.1)$ & $25.2(17.8)$ \\
\hline mPAP, mean, (SD), mmHg & $26.2(15.1)$ & $47.4(16.1)$ \\
\hline \multicolumn{3}{|l|}{ Early complications, n (\%) } \\
\hline Massive hemorrhage & $1(2)$ & 0 \\
\hline Embolization & $4(8)$ & 0 \\
\hline Transient dysrhythmia & $15(31)$ & 0 \\
\hline $\begin{array}{l}\text { Ejection fraction } 1 \text { day after } \\
\text { procedure, mean (SD) }\end{array}$ & $67.8(10.1)$ & NA \\
\hline \multicolumn{3}{|l|}{ Outcome, n (\%) } \\
\hline Survive & $47(96)$ & $5(100)$ \\
\hline Died & $2(4)$ & 0 \\
\hline
\end{tabular}

$\mathrm{NA}=$ not analyzed; $\mathrm{SD}=$ standard deviation; $\mathrm{PA}=$ pulmonary artery; $\mathrm{mPAP}=$ mean pulmonary arterial pressure 


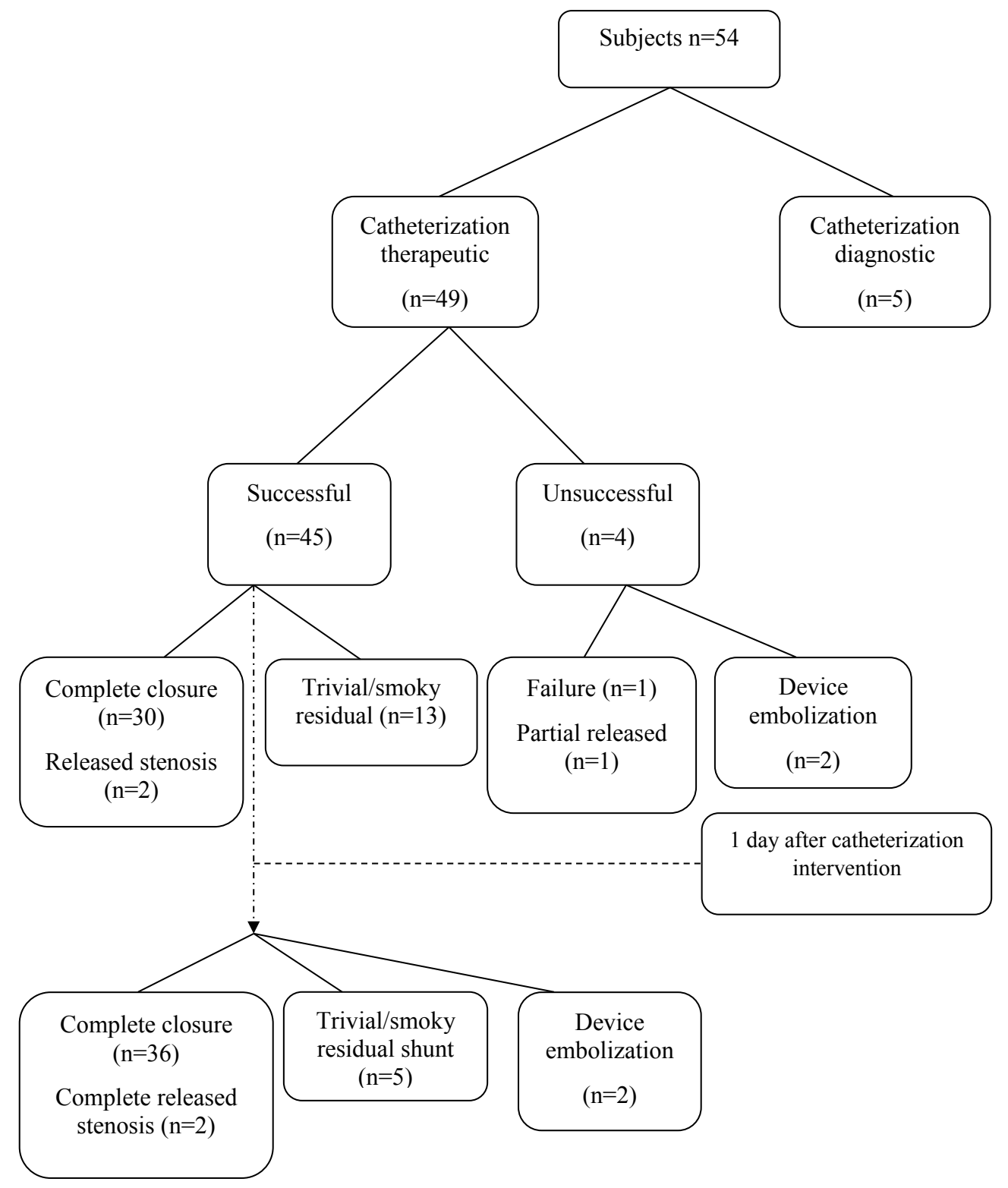

Figure 1. Diagram characteristic GUCH patients

(Table 2). Echocardiography evaluation on first day after therapeutic catheterization procedures showed 36 subjects had complete closure, 5 subjects has residual shunt and 2 subjects as device embolization (Figure 1).

\section{DISCUSSION}

Congenital heart disease is a broad malformation spectrum in the heart and aorta, which reaches rate of 7.1 per 1,000 live births in Oman, over one million population in the United States and 1.2 million population in Europe.
Grown-up congenital heart disease is one of the clinical issues being developed by pediatric cardiology and adult cardiology.,4 After catheter ization was introduced for the first time, it was found that interventional catheterization is beneficial for pediatric patients because of less invasive procedure, which then extended to adult patients. ${ }^{7,8}$ Due to the advancement of pediatric cardiology, cardiac surgery, and critical care, more babies born with congenital heart disease may survive to adulthood and survive at the rate of $85-90 \% .{ }^{9,10}$ The types of congenital heart disease that have been found and corrected in patients with GUCH disease commonly are 
ASD, VSD, tetralogy of Fallot (TOF), and PDA. ${ }^{11}$ GUCH is a congenital heart disease that has been present since birth. The problems will begin to appear when the children reach adulthood like physical activity disturbance such as dyspnea, palpitation, chest pain, fatigue, and abnormal heart sound. The condition was similar to the study in Japan, in which GUCH may be diagnosed in patients with palpitation, arrhythmia, or progress of congestive heart failure. ${ }^{6}$ The defect should be closed but not all intervention can be done. If there has been primary pulmonary hypertension, it's too late to do the closure intervention.

Therapeutic catheterization in this report was done in 49 (91\%) similar with that reported in UK which was 85\%. In Pakistan, the number of intervention reached 105 (50.4\%) out of 208 patients. ${ }^{3,12}$ The median age of patients who underwent catheterization intervention were 23 (range 13-59 years old), in which women was higher at $38(70,4 \%)$. The youngest GUCH's patient in Sanglah Hospital was 13 years old, it'sbecause the limit age of pediatric patient in Sanglah Hospital under or equal 12 years old. In Oman and Aga Khan University, the average age of GUCH patients who underwent catheterization intervention was $31.0 \pm 13.8$ years old, where cases in women slightly higher at $99(50.8 \%)$ than men. ${ }^{1,3}$

Catheterization intervention that took place at Integrated Cardiac Center Sanglah Hospital for congenital heart disease was ASD correction in 24 (44\%) cases, followed by PDA in $16(30 \%)$ cases, and VSD in $11(20 \%)$ cases. The results were similar with the data from Aga Khan University in which interventions in GUCH patient were on ASD (55.3\%), followed by VSD (26.2\%), TOF (12.8\%), and PDA (1.5\%). ${ }^{1}$ AASD is a common congenital heart disease which accounts for $8-10 \%$ of all congenital heart disease (CHD) and is considered to be the most common type of CHD in adults. ${ }^{12}$

In this study, defect closure was successful in 45 cases (91\%), and unsuccessful in 4 cases (7\%), similar with Japan $(93 \%){ }^{7}$ Immediately after device implantation, trivial or smoky residual shunt was detected in 13 (29\%) subjects and this residual was decreased one day after procedure. That condition were similar to transcatheter ASD closure in adult at Cipto Mangunkusumo Hospital. ${ }^{11}$ Residual shunt may be due to different types of device implanted (not showed in this study).

In 5 cases which undergone diagnostic catheterizations only 3 cases were ASD with pulmonary hypertension and 2 VSD DCSA with RCC prolapse. The five cases indicated as failure cases or not-closed had the mean pulmonary arterial pressure (mPAP) $47.4 \mathrm{mmHg}$; which was higher than the success cases with the mPAP $26.2 \mathrm{mmHg}$. Pulmonary hypertension is a hemodynamic and pathophysiological condition defined as an increase mPAP $>25$ $\mathrm{mmHg}$ at rest, or mPAP $>30 \mathrm{mmHg}$ at exercise as assessed by right heart catheterization..$^{13}$ There were various factors contributing to pulmonary hypertension or crisis in postoperative period such as presence preoperative hypertension (PAP $>50 \mathrm{mmHg}$ and pulmonary venous return (PVR 8.6 Wood Units), increased sympathetic tone, hypoxia, ischemia-reperfusion injury, fluid overload, positive pressure ventilation, left ventricular systolic or diastolic failure, acidosis, acute lung injury. Increases in right ventricle afterload due to an acute increase in PAP may precipitate right ventricle failure and lower stroke volume and arrhythmia. ${ }^{14}$ Remodeling of the right ventricle and the right atrium in response to long standing pressure and volume overload appears to generate the underlying arrhythmogenic substrate. Cardiac arrhythmia are important contributors to morbidity and mortality in patients with pulmonary arterial hypertension. ${ }^{15}$ Our patients has arrhythmia (ventricular tachycardia) and it's related to preoperative pulmonary hypertension, contributed to left ventricular dysfunction and mortality.

The minor complication was bleeding at puncture site $(69 \%)$. On the other hand, major complications reported were massive bleeding in the vascular heart (2\%) caused by i.e big catheter, used more than one catheter, and intervention was too long and difficult; embolization (8\%) and transient dysrhythmia (31\%). Study in Poland showed from 488 patient underwent transcatheter closure, there were no serious complications, no device embolization, and no fractures of the device, but only minor complication were recorded in 10 (13\%) 
patients with minimal venous access bleeding without transfusion. ${ }^{16}$ Overall complications rates were low after transcatheter device occlusion.

The most unwanted complication is device embolization. Smaller rims surrounding a large defect may technically complicate successful device placement thus increasing the risk of embolization in ASD. Deficient anterior-superior rims of large ASD may increase the chance of contact between the device and the atrial wall. ${ }^{17}$ In our study, embolization occurred in 2 subjects with large ASD, 1 of VSD subject, and 1 of PDA. All of the procedures were assessed under transthoracic echocardiogram (TTE), which were influence to the outcome.

There were only 2 patients (4\%) who died post-catheterization due to pulmonary hypertension crisis and dysrhythmia such as ventricular tachycardia. This was similar to fatal cases in Japan, in which 2 patient died $(6.6 \%)$ during the follow-up period caused by prostatic cancer and severe chronic obstructive pulmonary disease and mid left ventricular dysfunction. In Aga Khan University also 2 patients died (1\%) caused by arrhythmia and septicemia. ${ }^{1,7}$

There were some limitations in our study. We didn't used nitric oxide (NO) for standard vasoreactivity test and treatment pulmonary hypertension crisis in this center. This was a retrospective study with a limited number of cases. Immediate evaluation post-device implantations were assessed with TTE which was different from trans-esophageal echocardiography examination (TEE) modality worldwide. Complications of device implantation is ideally observed in a long period of time. Our observation time was relatively short.

In conclusion, GUCH patients were treated in Sanglah Hospital with 91\% undergone interventional catheterization. ASD closure was the most common procedure. Transcatheter intervention has a high procedural success rates (96\%) and low procedural-related complications.

\section{Conflict of Interest}

The authors confirm no conflict of interest in this study.

\section{REFERENCES}

1. Shahabuddin S, Hashmi S, Rakhshan SE, Khan JK, Sami SA, Amanullah M. Is grown up congenital heart (GUCH) disease different in a developing country? J Pak Med Assoc. 2016;66 (Suppl 3)(10):S5-7.

2. Arzamendi D, Miro J. Percutaneous intervention in adult congenital heart disease. Rev EspCardiol (Engl Ed).2012;65(8):690-9.

3. Somerville J. Grown-up congenital heart (GUCH) disease: current needs and provision of service for adolescents and adults with congenital heart disease in the UK. Heart. 2002;88Suppl 1:11-14.

4. Sukmana TP, Mulyadi MD, Nikmah SI, Hasri S, Sidigdo S. Transcatheter closure of atrial septal defects in a center with limited resources: outcome and short term followup. Iran J Pediatr. 2015;25(6):1-5.

5. Baumgartner H, Philipp B, Natasja MS, Fokko de H, John ED, Nazzareno G, et al. ESC guidelines for the management of grown-up congenital heart disease (new version 2010). Eur J Heart. 2010;31(23):2915-57.

6. Akagi T. Current concept of transcatheter closure of atrial septal defect in adults. J Cardiol. 2015;65(1):17-25.

7. Akagi T. Catheter intervention for adult patient with congenital heart disease. J Cardiol. 2012;60(3):151-9.

8. Greutmann M, Tobler D, Kovacs AH, Greutmann-Yantiri M, Haile SR, Held L, et al. Increasing mortality burden among adults with complex congenital heart disease. Congenit Heart Dis. 2015;10 (2):117-27.

9. Diller GP, Gunter B, Helmut B. Congenital heart defect in adulthood. DtschArztebl Int. 2011;108:452-9.

10. Gurvitz M, Kristin MB, Ralph B, Craig SB, Curt JD, Stephanie MP, et al. Emerging research directions in adult congenital heart disease a report from an NHLBI/ACHA working group. J Am CollCardiol. 2016;67(16):1956-64.

11. Al-Balushi A, Hamood AK, Homood AS, Suresh K, Salim AM. Adolescent and adults with congenital heart disease in Oman. Oman Med J. 2015;30(1):26-30.

12. Sultan M, Asif M, Maad U, Nadeem S, Khurram A, Hajira A. Cardiac catheterization in grown-up patients with congenital heart disease-indications and complications. Pak Heart J. 2012;45:174-9.

13. Galie N, Marius MH, Marc H, Adam T, Jean-Luc V, Joan $\mathrm{AB}$, et al. Guideline for the diagnosis and treatment of pulmonary hypertension: The task force for the diagnosis and treatment of pulmonary hypertension of the European Society of Cardiology (ESC) and the European Respiratory Society (ERS), endorsed by the International Society of Heart and Lung Transplantation (ISHLT). Eur J Heart. 2009;30:2493-537.

14. Minai OA, Yared JP, Kaw R, Subramaniam K, Hill NS. Perioperative risk and management in patients with pulmonary hypertension.Chest. 2013;144 (1):329-40.

15. Rajdev A, Hasan G, Angelo B. Arrhythmias in pulmonary arterial hypertension. ProgCardiovasc Dis. 2012;55:1-10.

16. Komar M, Tadeusz P, Maria O, Bartosz S, Piotr P. The benefit of atrial septal defect closure in elderly patients. ClinInterv Aging. 2014;9:1101-7.

17. Meyer MR, David JK, Alain MB, Oliver K, Frans RE. Efficacy and safety of transcatheter closure in adults with large or small atrial septal defects. Springerplus. 2016;21(5):1841. 